\title{
The lived experience of Insider Action Research in a local government setting
}

\author{
Adele Kenneally ${ }^{\mathrm{a}}$ \\ ${ }^{\mathrm{a}}$ Community and Culture, Glenelg Shire Council, adelekenneally@iinet.net.au
}

\begin{abstract}
Insider Action Research is undertaken by researchers within their own organisation. The researcher is an 'insider', or a complete member of the organisation and not one who joins the organisation temporarily for the purpose of the research. Action research involves cyclical planned interventions or actions, study and review of the actions, then further revised action. This paper describes the lived experience of carrying out Insider Action Research as a senior manager undertaking a $\mathrm{PhD}$ in a large rural council in Victoria. Although the insider has access to internal intelligence which can be useful in addressing and solving practical problems in organisations, this approach is not without its difficulties which can arise from the political and personal dimensions of undertaking research within one's own organisation. Challenges arise from the tension between the need to be close to the setting and, at the same time, the need to maintain distance in order to be objective and to be able to stand back, assess and reflect. Ethical challenges and role conflict are some of the dilemmas confronted by the researcher, and in the fast moving life of the organisation, the mental and emotional energy required to work through these dilemmas is considerable. Nonetheless, Insider research can also be rewarding and has the potential to provide an avenue for self-development and self-knowledge.
\end{abstract}

\section{Setting the scene}

The setting for this research was a large rural local government authority located in Victoria. In 2005-06, Council was not enjoying a good reputation, largely due to some unpopular governance decisions and negative media coverage. As a consequence, the staff appeared to share a siege mentality, with feelings of helplessness, victimisation and defensiveness. In 2007 Council had poor results in every key measure of performance as measured by the Community Satisfaction Survey undertaken by the Victorian Government .

I commenced a research project as part of studies towards a $\mathrm{PhD}$ in 2007. By this stage, I had been a senior manager with Council for two years and I was looking to 
improve my professional practice and gain a better understanding of local government. Although somewhat naive, there were two things that I wanted to see happen:

1. Improvement in the way Council (as an organisation) was perceived and viewed by the residents and citizens of the shire

2. Mobilisation of the residents, citizens, organisations and agencies of all tiers of government to address the significant health and disadvantage issues of the shire.

The need to be participative underpinned my approach to this research. My intention was to 'involve all relevant parties in actively examining together current action [which they experience as problematic] in order to change and improve it' (Wadsworth 1998). My intention was to be genuinely democratic; with the Council management team acting as the critical reference group, we would examine the issues and seek solutions with all parties involved in the discussions. I had anticipated that the methodology that I would be using would be action research, and I intended that this approach would encompass a participative action research style. However, as the research evolved and I developed an enhanced understanding of methodology through the literature, I realised that it was better described as 'Insider Action Research’ with an ethnographic dimension.

The process of Insider Action Research is complex, demanding and unpredictable, with many contradictions, tensions and dilemmas. In a metaphoric sense, it is an organic and dynamic journey. The action research journey can be likened to Alice's journey in 'Alice in Wonderland' (Carroll 1865). It is often a coming of age story and a story of personal growth in a land where frequently there doesn't appear to be much sense or logic.

\section{What is Insider Action Research?}

My research objectives involved developing my skills, gaining understanding and improving aspects of the practices of Council's workforce. I chose action research as the methodology as it provides an explicit link between a systematic enquiry and changes in practice. Changes or improvements are achieved thorough 'cycles of investigation, action, and reflection, while at the same time reporting it in a way that is useful to both to the project in hand and potentially to outsiders' (Costley, Elliott \& Gibbs 2010, p. 88). Insider Action Research also has the advantage of providing the researcher with the opportunity to reflect and develop their own practice, providing an added personal dimension to the research for deeper learning and self-development, and to develop real knowledge and insights into the organisation. 
As noted, Insider Action Research is undertaken by researchers within their own organisations. It differs from traditional action research where the action researcher and a client collaborate in the diagnosis of a problem and in the development of a solution based on the diagnosis (Bryman 2004; Coghlan 2003). In Insider Action Research, the researcher is an 'insider', or a complete member of the organisation, and not one who joins the organisation temporarily for the purpose of the research.

According to David Coghlan, 'in Insider Action Research the researcher is not only concerned with studying some aspect of the organisation, but with changing it' (2003, p. 456). Insider Action Research also has an ethnographic dimension as the researcher is immersed in a setting, and gathers data through the acts of observing and listening to what is being said within that setting. In this project, there were times where I became more of a participant observer: watching behaviour, listening to conversations, and asking questions with additional data collected through interviews, surveys and the collection of relevant documents.

The Insider Action Research approach provides a number of advantages over the traditional research approach. Firstly, it is valuable because it reflects the experience of practitioners who are complete members of their organisations, and it has the potential to make a unique contribution to organisational research, especially in relation to how they change and how individuals understand and undertake their roles within that environment. It can also be useful in providing deeper understanding of change management and can 'enable the deeper aspects of organisational change to be uncovered and researched' (Coghlan 2003, p. 461).

Secondly, the researcher is immersed in the environment and therefore has relatively open access to the internal environment with regular interaction with the members of the organisation and even potentially an easy passage through the organisation. Bryman discusses the difficulties for researchers in gaining access to groups and closed settings (2004, p. 297), however this is not so difficult for the insider; the ongoing member of the organisation. The insider has access to internal intelligence which can be useful in addressing and solving practical problems in organisations.

\section{Challenges of this approach}

Despite the strengths of Insider Action Research, this approach is not without its difficulties. One of the difficulties of using Insider Action Research as a methodology, particularly for a $\mathrm{PhD}$, is that the often linear structure of a $\mathrm{PhD}$ project is generally suited to a more traditional research approach. As Sarah and others have noted, there is a tension between these requirements and 'an action research mindset of emergence where 
you start with a "loose idea" that allows for outcomes to unfold and reveal themselves through cycles of action and reflection within a dynamic context' (Sarah et al. 2002, p. 536). Action research does not necessarily involve the testing of a hypothesis; rather, it allows the researcher to develop knowledge or understanding as part of practice. The need for a nominal beginning and end point in a research project is also limiting in the continuous world of the organisation and the work of the practitioner. As Sarah and others also note, a pragmatic approach is required to accommodate the 'project mindset' within an 'action research' mindset (Sarah et al. 2002, p. 540). This does not just apply to $\mathrm{PhDs}$, but also to the linear structure of most project plans within organisations.

There are also occasions when there may be an insider-outsider dichotomy in play. As a woman in a male management team, and as a researcher undertaking academic research in a community where education is not highly valued, there were times when I felt like more of an 'outsider' than an insider.

Other difficulties can arise from the political and personal dimensions of undertaking action research within one's own organisation. There are a number of considerations with regard to power shifting within the organisational environment, particularly in a local government setting where there are scarce resources, and a fairly rigid organisational structure with rules and regulations. Changes in personnel and councillors often affect interpersonal alliances, networks and control of knowledge and information. This can lead to uncertainty within rapidly changing environments that ultimately affects the sustainability of the project.

Over the period of this research project, Council employed three different Chief Executive Officers. The members of the management team also experienced a 50\% turnover rate during this time. Electoral cycles and political cycles can also affect the sustainability of action research projects. In November 2008, Council elections resulted in three (out of seven) new councillors. This changeover precipitated a change in the dynamics, priorities, and ways of working within Council.

Whilst organisational politics can pose challenges for the Insider Action Researcher, another real challenge results from the tension between the need to be close to the setting and at the same time maintain distance in order to be objective and to be able to stand back, assess, and reflect. The researcher and participants also come to the project with their own preconceived ideas, their own experiences, and world views. This can lead to a range of differing assumptions and sometimes misunderstandings.

Because it is undertaken by insiders, this approach to research therefore needs to be robust. Advocates of this approach, such as Brannick and Coghlan, acknowledge the need for a robust and systematic approach. They assert that it is valid and useful in providing important knowledge about 'what organisations are really like' (2007, p. 72). 
They go on to contend that the advantages of Insider Action Research include gaining primary access to the organisational system, as well as access to the documentation, data, people and meetings (depending on the research topic and political perception of that topic). They discuss 'preunderstanding' of the organisational dynamics and the 'lived experience' of the researcher's own organisation as advantages for the Insider Action Researcher.

\section{Ethics and ethical challenges}

This research project was multidimensional and data was gathered from a range of stakeholders, including local citizens, elected local government representatives, senior executives from Council, work colleagues and other staff. Each stakeholder group posed particular methodological and ethical challenges. In particular, I was conscious that some of these stakeholders may have felt vulnerable.

Insider Action Research confronts particular ethical challenges (Holian 1999; Ferguson 2001; Coghlan 2007). The dilemma most frequently described in the literature is that of role conflict and the ethical issues arising from the difficulty of managing the dual roles of practitioner and researcher. When information is provided by colleagues and other members of the workplace, it may be difficult to ascertain whether it is provided in confidence to the researcher, or the senior manager in the organisation. If it is provided to the senior manager they may be obliged to act on it, particularly if it has the potential to prevent harm to others. There are occasions where this may be avoided by clarifying the role of researcher / practitioner with the person providing the information; however this may not always be possible. There is also the difficulty of maintaining the distinction when recalling this information; was this piece of information provided to the researcher or the senior manager? And what course of action, if any should be undertaken? Detailed notes and the journal entries helped. In the fast moving life of the organisation, the mental and emotional energy required to work through these dilemmas was considerable.

Holian and Brooks (2004) pose a number of ethical questions for consideration by potential insider researchers including the nature and extent of the level of informed consent, the ownership of the data, the nature of the relationship between the researcher and the participants or subjects, and the nature and extent of anonymity and confidentiality for individuals and the organisation

I dealt with these issues in this research project by:

1. Informed consent 
- Where data were collected through interview or survey, participants could choose to be part of the research project. They were given the opportunity to self-nominate after they had received details of the research project. I also described the project in the Council staff newsletter to create awareness of the research. Information about the project and further requests for volunteer participants were also later distributed via email to employees.

- Information about the project was presented to the management team and Council.

- All participants (staff and councillor interviews, and community surveys) were provided with a copy of the project information statement, and were given the opportunity to ask questions and then asked to sign the consent form.

2. Ownership of the data

- Most of the organisational data was available in the public domain (e.g. annual reports or council meeting minutes). Other data was aggregated.

3. Relationships

- Employees who reported directly to me were not included in this study.

- Participants were asked to forward their nomination to an independent third party - this was intended to avoid any potential for employees to feel compromised and it was anticipated that this would strengthen the validity of the study. The independent third party also checked the willingness of the volunteers to participate and ensured that they felt comfortable.

4. Protection of participants

- In order to maintain confidentiality, pseudonyms were used for staff members, councillors and other participants.

- The community survey participants were unrecognised in this research. The surveys were addressed to "the householder" and the addresses were randomly selected from Council's rates database.

In this project I also encountered a more challenging issue. As Holian and Brooks note, a potential problem for insider research relates to the potential to 'encounter problems due to unexpected and potentially negative or even dangerous outcomes for organisations and individuals' (Holian \& Brooks 2004). There is the potential for damage to the organisation's reputation and relationships where information is not handled 
sensitively. The findings may also have political consequences and the potential to damage reputations or even end the employment of the researcher by the organisation. In this research project, where there were any ethical questions of this nature, I chose to exclude the discussion of some events and findings in order to protect the organisation and individuals within the organisation from potential identification.

\section{Research methods}

The research methods are the vehicle for delivering a robust research project. Unlike other forms of research, an action approach can rarely be finalised at the outset since 'it is a process through which solutions and insight are generated in an explorative manner'(Williamson 2000, p. 147). There are, however, a number of techniques that can be applied in order to ensure that this type of research can be carried out in a rigorous manner to generate reliable and, to use Kemmis's notion, 'truthful' data (Kemmis \& McTaggart 2000).

The following tools were utilised to collect the data:

1. Research Journal

The research journal was a key component of this project and provided four principal functions:

- To record observations. The day to day work of a practitioner-researcher is busy with many things happening, often at the one time. The journal was used to note events, conversations, and various meeting outcomes to assist with recollection.

- As a means of catharsis. The journal was utilised to vent emotions, in particular those of frustration and at times of anger.

- A place to record reflections on action. The journal was utilised to stimulate thinking about experiences based on the actions and decisions of the action research cycle.

- To analyse reflections and to connect with the relevant literature.

\section{Interviews}

In the qualitative interview, the researcher aims to acquire rich detailed answers (Bryman 2004, p. 320). This objective shaped my approach to the staff interviews conducted as part of this research project. Although there was a set of interview questions, the interviews were semi-structured to gain the perspectives and points of 
view of the interviewees. The semi-structured interviews provided insight into what the interviewee saw as relevant and important, and enabled the interviewer to ask new questions and vary the order and, in some cases, the words of the questions.

\section{Surveys}

I believed that I had a responsibility to be as informed as possible before taking purposeful action. As a consequence, part way through my research I surveyed residents to gain a snapshot of their level of satisfaction with Council services, facilities, staff, and councillor performance. My intention was to use these data to identify specific areas for action. These provided me with a 'taste' of community perception and mostly confirmed what I had already perceived through other avenues of community work.

\section{Informal discussion, conversations, and meetings}

Throughout the course of the project, informal discussion and conversations were held via phone, email, and face to face at meetings and other forums. This was the ethnographic dimension of the project. I was also a participant observer who observed interaction, listened to conversations, examined documents, and made notes on these impressions and experiences. This was simple and unstructured; there wasn't an observation schedule and in many cases I had no influence over the situation being observed. This approach also provided me with the opportunity to observe and listen in order to inform the planning of any actions and also to gain an appreciation of the effects of any actions. Although I captured some of these events in my notes, I often relied on my memory to record conversations later in my research journal.

\section{A taste of doing the research}

I commenced the data collection phase of my research with a plan to raise awareness of what I was doing within the organisation. This involved a series of presentations, briefing papers and articles in the staff newsletter. It was a busy time of the year with the budget process underway. I was unable to engage either the management team or councillors and they seemed disinterested, offering just a few desultory questions and expressions of good luck. At this stage I felt paralysed by indecision and anxiety, nonetheless I pushed on with the staff and councillor interviews. On reflection, it wasn't the best timing, but one can never know in local government when it is the right time. I also found myself in somewhat of a dilemma: I didn’t want to draw any more attention to myself as I had received some derisory comments about 'being an academic', but I needed to promote my research in order to attract participants. This tension between not 
wanting to draw negative attention and yet wanting the other managers and the councillors to engage with the research was difficult and challenging, but it was a matter of pride - I couldn't retreat.

I kept going with the data gathering but, at this stage, I could see that I wasn't going to be able to influence the organisational culture as I had planned, and it certainly wasn't the participative process as I originally envisaged. I continued with the interviews over the next two months, and became aware that data from the staff interviews in particular was skewed towards the negative as they were using my project to vent their frustrations and dissatisfaction with their work environment. I encountered another dilemma - as the staff I was interviewing were from other parts of the organisation, it was going to be difficult for me to develop 'actions' in response to what I was learning. I didn't have direct influence in other areas of the organisation and I couldn't raise specific issues with the other managers as they had been related to me in confidence.

I became alarmed and worried about some of the descriptions of perceived intimidation, unprofessional practices, and some cases of poor customer service that were being provided through the interviews. I was feeling conflicted from the tensions arising between passing on the information and the confidentiality of the information being provided. As Holian notes, 'determining and maintaining the boundaries between the roles of senior executive and researcher required constant vigilance', often causing ethical dilemmas (Holian 1993, p. 3). I did eventually act and sought ways of bringing them to the attention of the management team by obliquely referring to some things at our meetings as the opportunities arose. For example, when discussing organisational training needs, I suggested that all employees would benefit from customer service training, not just front line staff. It was in this way that I raised the issues without alluding to my research or the interviews. Sometimes it was successful, and sometimes not.

As I continued with the data collection over the next few months, I also struggled with distinguishing between what was being said in meetings and open conversations, and what I had been told in confidence. The difficulties associated with the role duality of researcher and organisational member is widely discussed in the insider research literature (Ferguson \& Ferguson 2001; deGuerre 2002; Coghlan 2003; Bjorkman \& Sundgren 2005; Humphrey 2007; Coghlan 2007; Brannick \& Coghlan 2007; Moore 2007). I read and reflected on this literature, and as I found solidarity with other researchers who had routinely encountered this duality and other similar dilemmas, I was encouraged to continue my own work.

Over the next few months, I developed ways of dealing with the conflicts inherent in the insider research approach. I decided that the best way of dealing with the duality 
dilemma was to become more circumspect and say less until I had the time and space to reflect on the responses and data and develop some objectivity. In other words, I captured it in my journal, but I didn't act on it until I had more time to think about it.

My research was taking place against the backdrop of the usual Council business of councillor briefings and meetings, and the actual business of service delivery and governance. There were times when I had to put the research project on the back burner and focus my energy and time on my work.

Part way through the project I took some time out for serious thinking and reflection. This provided me with the space to objectively consider what I had been doing and how I was going to approach the next stages of the project. Instead of focusing my energies outwardly, I decided to examine my own practice and implement what I had learnt in my own department. I was quietly hoping that, if I was successful, some of these interventions might also be taken up by others across the organisation.

And so, over the next 6 months, it seemed that it was a few steps forward and then a few steps back (and one or two sideways). Overall, there was limited progress in organisational development, but I was able to undertake some actions and interventions on the basis of my research.

\section{Making sense of the experience and the data}

Although Coghlan and Brannick assert that writing is 'the key to synthesis; where things begin to make sense, and meanings form', I found this part to be the most difficult part of the project. I found this process far more arduous and chaotic than that espoused in much of the literature. There were countless times when I lost my way and despaired of ever finding a way to capture the essence of my research. The neat thesis writing cycles described by Coghlan and Brannick (2010, p.142) and Zuber-Skerritt and Fletcher (2007, p. 421) did not reflect my disordered and eclectic experience.

My intention had been to write a chronological account. However, I found it difficult to make sense of the research and write it as a moment by moment narrative when I was still working in the same environment, on the same projects, and with the same people. I had changed; the work-research environment had moved on and was often very different. It was challenging to work in this dynamic, demanding environment whilst having to think and make sense of a completely different place. My workplace had changed over the period of this research project. I was working in a different environment, but I was also looking backwards and trying to make sense of the earlier workplace. Moving from space to space was a struggle as I grappled with the complexity of the different 
landscapes. I was frustrated and, in order to deal with this, found myself imposing order on my writing to be able to make some sense of and communicate the work and research.

This research process was also not that of a nicely staged action research project. The actual reality of the workplace contradicts the orderly cycles of action research as described by Cherry (1999, p. 2) and Coghlan and Brannick as a process of 'consciously and deliberately planning, taking action, reflecting and evaluating the action leading to further planning and so on' (2010, p. 5). Although there is discussion of the messiness of this approach in the literature, there is almost no mention of the personal and emotional aspects and their potential effects on the research. In the real workplace, when the researcher is also working with the community, councillors, and other managers, priorities change and the unexpected often occurs to disrupt any planning or planned actions.

Doing action research in one's own organisation is often muddled and convoluted. I was not autonomous and the personal nature of the approach is exacerbated in a country town. No-one can prepare you for the difficulties of research in one's own workplace.

My initial intention was to undertake action research and to write it as well formed cycles of planning, action and evaluation leading to more cycles. However, this was not my experience.

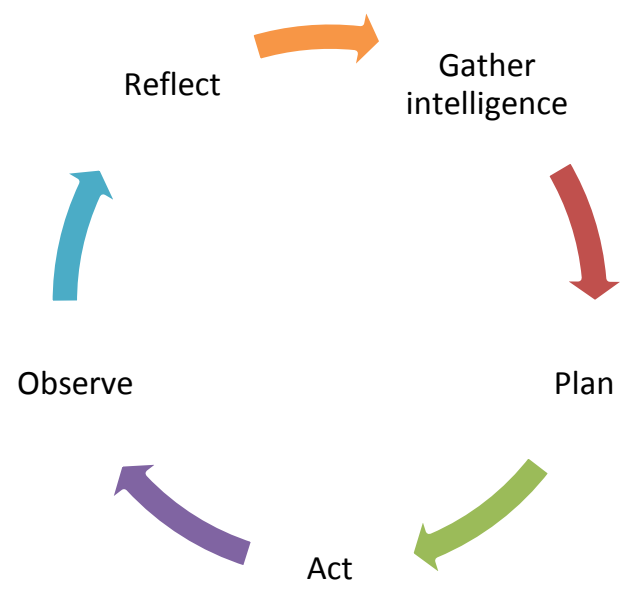

Fig. 1. Orderly cycle of action research

I frequently deviated from the standard action research methodology. I therefore did not write a contemporaneous account of the research, but instead worked towards imposing some order on the messy world of practice and selecting strands of related activities and events.

- Strand A described the research process and the dilemmas and emotions when things did not go as planned. 
- Strand B dealt with my endeavours to work within a kaleidoscope of disadvantage, with the differing but related lenses of distance, disadvantage (both socio-economic and educational), and demographics (ageing and a shrinking population).

- Strand C focused on the community dimension and relates to my endeavours to improve the way that local government engages, communicates, and works with the community.

- Strand D described the struggle to improve the responsiveness and work practices of local government.

- Strand E focuses on the personal dimension of working as a female senior manager in rural local government.

These strands represented my accounts of activities and events, and were limited in that they represented only one part of the story; one linked segment of the whole. They were one subjective version of events, reflecting my values and understandings. In this manner, I privileged some events over others where they were significant to the research objectives.

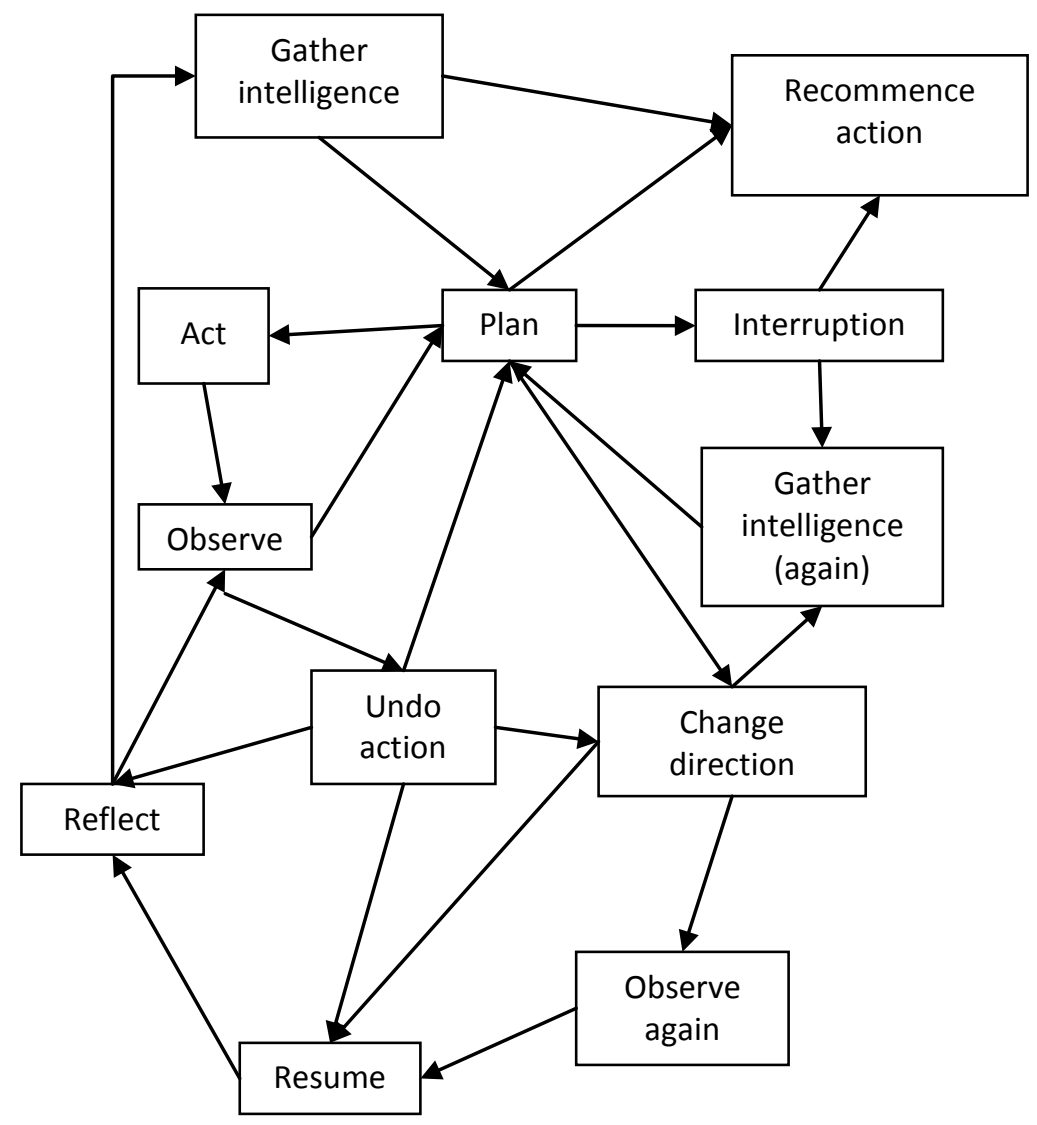

Fig. 2. Messy nature of Insider Action Research experience 


\section{Reflections at the end of the journey}

Undertaking full time work and study is difficult and exhausting. Undertaking Insider Action Research adds another dimension as it takes an emotional and physical toll as the researcher grapples with the challenges of thinking 'in layers' and dealing with the complexities of 'acting, thinking and doing' at several levels at once. For example, chairing a meeting, taking notes and thinking from a research perspective, as well as dealing with the meeting's central purpose is difficult and requires concentration and a great deal of energy. The researcher needs to think: How do I manage and progress this meeting? What is going on here? Is this relative to my research? How can I capture it? What about the ethics and the politics? How can I include this without being seen to criticize an individual or organisation? There are additional tensions due to the need to accurately reflect events, actions and interventions, balanced with the need to protect and disguise individuals, groups, or the organisation.

Moving from the role of researcher back to the role of practitioner is frequently conflicting and confusing and requires great concentration. In some instances, the researcher needs to develop clear strategies to deal with the conflict.

There are often ethical dilemmas throughout the course of an Insider Action Research project. Dealing with information provided 'in confidence' that has ramifications from a risk management and/or legal perspective poses significant ethical dilemmas for researchers and can lead to internal conflict, feelings of guilt, and intense worry about the possible outcomes. Dealing with these emotions is also tiring and difficult.

It is important to consider and reflect on the assumptions that underpin the project design and methodology at the outset of the research. (And, of course, this reflection needs to be an integral component of the research process.) How realistic are they? At the outset, I had based my project on the assumption that the management team would undertake a participative style of action learning that would apply to the whole organisation. I made this assumption without discussing it with the team prior to the beginning of the project. It was naïve to assume that I would be able to engage them in a participative action research approach, and consequently, the project didn't evolve down that path. Instead, I found myself having to redevelop this aspect and focus on the department that I managed. I was undertaking the action research on my own with little engagement or interest shown by the management team. It was a difficult realisation that undermined my self-confidence for a period of time and almost resulted in my withdrawal from the research program.

Insider Action Research, although very challenging, can also be rewarding. The messy nature of action research means that it is often a difficult journey, with the risk 
that the researcher may not emerge unscathed from the research (Moore 2007; Humphrey 2007). One of the more stressful and difficult components of this project was the writing of the final product. Organising all the data - the transcripts of the research journal, survey results, and interview notes - was arduous and awkward. Making sense of the data, interpreting it, and extrapolating it to 'a broader context' became time consuming and confidence sapping. There were periods when I felt that I hadn't done enough work for a $\mathrm{PhD}$, or that the outcomes were not significant or important enough. I struggled with the writing as I was trying to protect individuals and the organisation. It is important to allow enough time in the project plan for resolving these issues. I would also advise providing some distance from the workplace, for example taking time off work to enable objectivity and perspective at this stage of the project.

Nonetheless, Insider Action Research has provided an avenue for self-development and self-knowledge. It has enabled me to become a more knowledgeable and skilled practitioner and I have gained a greater understanding of local government. It has provided new information on the practice and experience of working as a manager in the complex and often turbulent environment of local government, and also has arguably provided real benefits for the community. Over the life of this project, a community satisfaction survey indicated a significant improvement in the community perception of Council's community engagement efforts with an increase of $17 \%$ of people rating Council's performance as good / excellent or adequate.

Through the project journey I went from an inexperienced and naïve local government manager who felt powerless and was rarely listened to, to acting chief executive officer.

In many cases, the saying by Nietzsche 'that which does not kill us makes us stronger' (1899) also applies to those intrepid explorers undertaking Insider Action Research.

\section{References}

Bjorkman, H. \& Sundgren, M. 2005, 'Political entrepreneurship in action research: learning from two cases', Journal of Organisational Change Management, vol. 18, no. 5, pp. 399-415.

Brannick, T. \& Coghlan, D. 2007, 'In defense of being "native”: the case for insider academic research', Organisational Research Methods, vol. 10, no. 1, pp. 59-74.

Bryman, A. 2004, Social research methods, 2nd edn, Oxford University Press, Oxford. Carroll, L. 1865, Alice in Wonderland, electronic book, eBooks@Adelaide, Adelaide. 
Cherry, N. 1999, Action research: a pathway to action, knowledge and learning, RMIT University Press, Melbourne

Coghlan, D. 2003, 'Practitioner research for organisational knowledge; mechanistic and organistic-oriented approaches to Insider Action Research', Management Learning, vol. 34, no. 4, pp. 451-63.

Coghlan, D. 2007, 'Insider action research: opportunities and challenges', Management Research News, vol. 30, no. 5, pp. 335-43.

Coghlan, D. \& Brannick, T. 2010, Doing action research in your organisation, 3rd edn, Sage, London.

Costley, C., Elliott, G. \& Gibbs, P. 2010, Doing work based research: approaches to enquiry for insider-researchers, Sage, London.

De Guerre, D.W. 2002, 'Doing action research in one’s own organisation: an ongoing conversation over time', Systemic practice and action research, vol. 15, no. 4, pp. 331-49.

Ferguson, P. \& Ferguson, B. 2001, 'Shooting yourself in the foot? An investigation of some issues in conducting insider research', Higher Education Research and Development Society of Australasia 24 ${ }^{\text {th }}$ Annual Conference, HERDSA, Newcastle, NSW.

Holian, R. 1999, Doing action research in my own organisation: ethical dilemmas, hopes and triumphs, paper no. 3, Southern Cross University Press, Lismore.

Holian, R. \& Brooks, R. 2004, 'The Australian national statement on ethical conduct in research: Application and implementation for 'insider' applied research in business', Action Research International, vol. 1, no. 7, pp. 1-21.

Humphrey, C. 2007, 'Insider - outsider: activating the hyphen', Action Research, vol. 5, no. 1 , pp. 11-26.

Kemmis, S. \& McTaggart, R. 2000, 'Participatory Action Research’, in N.K. Denzin \& Y.S. Lincoln (eds.), Handbook of Qualitative Research, Sage Publications, Thousand Oaks, CA, pp. 567-605.

McNiff, J. \& Whitehead, J. 2000, Action research in organisations, Routledge, London.

Moore, B. 2007, 'Original sin and insider research', Action Research, vol. 5, no. 1, pp. 27-39.

Sarah, R., Haslett, T., Molineux, J., Olsen, J., Stephens, J., Tepe, S. \& Walker, B. 2002, 'Business action research in practice - a strategic conversation about conducting action research in business organisations', Systemic Practice and Action Research, vol. 15, no. 6, pp. 535-45.

Wadsworth, Y. 1998, What is Participatory Action Research?, paper no. 2, Southern Cross University Press, Lismore. 
Williamson, K. 2000, Research methods for students and professionals; information management and systems, Charles Sturt University, Wagga Wagga.

Zuber-Skerritt, O. \& Fletcher, M. 2007, 'The quality of an action research thesis in the social sciences', Quality Assurance in Education, vol. 15, no. 4, pp. 413-36. 